\title{
Fatigue management experiences from women undergoing chemotherapy: self-care strategies ${ }^{a}$
}

\author{
Experiências de mulheres em quimioterapia no manejo da fadiga: estratégias de autocuidado \\ Experiencias de Mujeres en Quimioterapia sobre el Manejo de la Fatiga: estrategias de autocuidado
}

\author{
Nayara Ferreira Cunha ${ }^{1}(10)$ \\ Rosimár Alves Querino² \\ Paula Carolina Bejo Wolkers ${ }^{1}(\mathbb{D}$ \\ Anna Cláudia Yokoyama dos Anjos ${ }^{1}[$
}

${ }^{1}$ Universidade Federal de Uberlândia. Uberlândia, MG, Brasil.

2 Universidade Federal do Triângulo Mineiro. Uberaba, MG, Brasil.
Corresponding author:

Nayara Ferreira Cunha

E-mail: nayara.nfc@gmail.com

Submitted on $04 / 03 / 2019$.

Accepted on 07/11/2019.

DOI: 10.1590/2177-9465-EAN-2019-0097

\begin{abstract}
Objective: In order to understand the experiences of women with breast cancer managing fatigue due to chemotherapy with the use of non-pharmacological strategies. Methods: Explanatory study, qualitative, with theoretical reference of medical anthropology and resources of the ethnographic method for data collection; in which four women took part. Thematic analysis was performed based on interviews and conducted observations. Results: Three strategies of self-care, resulted from the culture were used for physical fatigue management: rest, energy conservation and eat habits. Physical activities, contact with plants and religiosity were constituted as practices to deal with emotional fatigue. We understand that the meaning attributed to the use of non-pharmacological strategies was the possibility of feeling capable, confident and able to continue treatment. Conclusions and implications for practice: These woman's experiences revealed the following necessities, the use of specific strategies to deal with fatigue, as well as the appreciation and understanding of their singularities and cultural practices present in their contexts. In the nursing care, it is possible to associate these practices with scientific knowledge and thus complement the care in favor of an integral care.
\end{abstract}

Keywords: Breast Neoplasms; Chemotherapy; Fatigue; Integrative and Complementary Health Practices; Self Care.

\section{RESUMO}

Objetivo: Compreender as experiências de mulheres com câncer de mama no manejo da fadiga secundária à quimioterapia com utilização de estratégias não farmacológicas. Método: Estudo explicativo, qualitativo, com referencial teórico da antropologia médica e recursos do método etnográfico para coleta de dados, em que participaram quatro mulheres. Foi realizada análise temática das entrevistas e de observações. Resultados: Três estratégias de autocuidado, provenientes da cultura, foram utilizadas para o manejo da fadiga física: descanso, conservação de energia e cuidado alimentar. Atividades físicas, contato com plantas e religiosidade constituíram-se como práticas para lidar com a fadiga emocional. Compreendemos que o sentido atribuído à utilização de estratégias não farmacológicas foi a possibilidade de sentirem-se capazes, confiantes e aptas para prosseguirem o tratamento. Conclusões e implicações para a prática: As experiências dessas mulheres revelaram necessidades, do uso de estratégias específicas para o manejo da fadiga, bem como da valorização e compreensão de suas singularidades e de práticas culturais presentes em seus contextos. Na assistência de enfermagem é possível associar estas práticas ao conhecimento científico e, assim, complementar o cuidado em prol da atenção integral.

Palavras-chave: Neoplasias da Mama; Quimioterapia; Fadiga; Práticas de Saúde Integrativas e Complementares; Autocuidado.

\section{Resumen}

Objetivo: Comprender las experiencias de mujeres con cáncer de mama en el manejo de la fatiga secundaria a la quimioterapia con la utilización de estrategias no farmacológicas. Método: Estudio explicativo, cualitativo, con referencial teórico de la antropología médica y recursos del método etnográfico para recolectar los datos, en que participaron cuatro mujeres. Se realizó un análisis temático de entrevistas y observaciones. Resultados: Se utilizaron tres estrategias de autocuidado, provenientes de la cultura, para el manejo de la fatiga física: descanso, conservación de la energía y cuidado alimentario. Las actividades físicas, contacto con plantas y religiosidad se constituyeron como prácticas para lidiar con la fatiga emocional. Comprendemos que el sentido atribuido a la utilización de estrategias no farmacológicas fue la posibilidad de sentirse capaces, confiados y aptas para proseguir el tratamiento. Conclusiones e implicaciones para práctica: Las experiencias de estas mujeres revelaron necesidades del uso de estrategias específicas para el manejo de la fatiga, así como de la valorización y comprensión de sus singularidades y de prácticas culturales presentes en sus contextos. En la atención de enfermería es posible asociar estas prácticas al conocimiento científico y así complementar el cuidado a favor de una atención integral.

Palabras clave: Neoplasias de la Mama; Quimioterapia; Fatiga; Prácticas Integradoras y de Salud; Autocuidado. 


\section{INTRODUCTION}

Chemotherapy is found among the forms of treatment for breast cancer and, even at therapeutic doses, adverse reactions are unavoidable. ${ }^{1}$ Among these, fatigue is an important and prevalent adverse reaction in women with breast cancer. ${ }^{2}$

For oncology, fatigue is defined as an agonizing, persistent, and subjective sensation characterized by physical, emotional, cognitive, or exhaustion fatigue. It is related to cancer or its therapy; ${ }^{3}$ that is, it may be related to chemotherapy, considered a secondary event ${ }^{4}$ in this case. It is not proportional to recent activity and interferes with the functional capacity, ${ }^{3}$ to the point of increasing the need for rest, changing concentration and leading to restriction in the performance of usual activities. Although it does not normally affect the performance of the treatment directly, it has a negative impact on the daily life and quality of life for cancer patients. ${ }^{1-2}$

Researchers have shown interest in identifying ways to attenuate this adverse reaction, with pharmacological and nonpharmacological treatments. Among the pharmacological treatments studied, there are corticoids, psychostimulants, ${ }^{1}$ as well as the treatment of other comorbidities or factors associated with fatigue such as pain, anemia, sleep disturbance and nutritional deficit. ${ }^{3}$

As complementary practices to conventional treatment, the literature describes phytotherapy, as Ashwagandha extract ${ }^{5}$ and ginseng, ${ }^{6}$ physical exercise, energy conservation, cognitive behavioral therapy, distraction, yoga, massage therapy, sleep hygiene, bright light exposure ${ }^{7,1,3}$ and hypnosis. ${ }^{6}$

The occurrence of chemotherapy secondary fatigue (CSF) in women with breast cancer requires that professionals and researchers seek appropriate strategies for better understanding and management, without ignoring individual and collective experiences in relation to the knowledge and use of sociocultural practices.

This research was developed in order to understand the experiences of women with breast cancer in the management of chemotherapy secondary fatigue with the use of nonpharmacological strategies.

\section{METHOD}

This is a clarifying, qualitative study, with theoretical orientation on the medical anthropology and strategies of the ethnographic method for data collect.

Medical anthropology analyzes how people from different social groups explain diseases, their causes, therapeutic resources, and ways for coping. ${ }^{8}$ It seeks to understand the culture and terms in which the experience was produced, investigates the subjective knowledge constructed through the reality lived by the individual, and explores how the stories related to the experience of the illness make sense to the person. ${ }^{9}$

Ethnography's techniques were chosen because they enable the researcher to move from their culture, to internally position themselves in the context of the experience in strategic places to better understand the symbolic world of their studied object, making it possible to see through closer lenses, to capture the senses attributed to the experiences and, later on, to construct the description through the analysis of the interpretation that each individual makes of the things, the events and the facts: elements based on culture. ${ }^{10-11}$

The eligibility criteria were: women diagnosed with stages I and II breast cancer, with intravenous chemotherapy-related fatigue, performing at the maximum the expected third cycle and who had used non-pharmacological strategies to seek relief from the adverse reaction.

Participants were selected for convenience. Recruitment took place in an oncology clinic of a public university hospital in the inland of Minas Gerais, Brazil. Fatigue was identified through applying the Fatigue Assessment Flowchart, ${ }^{12}$ and the PiperRevised Fatigue Scale, ${ }^{13}$ during nursing consultation held in an extension project linked to the undergraduate course, under the coordination of the fourth author. After confirming CSF, the confirmation on the use of some non-pharmacological strategy for its management was carried out and, if so, women were invited to take part in the study.

Considering the depth that the qualitative research requires, six women were selected initially. After the first interview, two were excluded. One due to the end of the treatment before the expected time and another because there was no fatigue after the recruitment. Thus, the group of participants was composed by four women, considering data theoretical saturation criterion. ${ }^{14}$

The investigation obeyed the precepts of Resolution 466/2012 of the National Health Council. The project was approved by the Ethics Committee in Research with Human Beings on April 29, 2015, under written opinion number 1.042 .720 and registration number CAAE 43007615.5.0000.5152. Anonymity of the participants was guaranteed by using pseudonyms chosen by them, being referred to as: Luíza, Lis, Lívia and Maya.

Data collect took place between June 2015 and July 2016, at the oncology outpatient clinic and at home, according to the participants' choice; always in a private place. For data collect, ethnographic method strategies were used: observation, semistructured interviews recorded in audio and notes in a field diary.

A semi-structured script was developed in order to define the initial content explored in the study, with questions guiding the interviews, such as: Can you tell me how it is for you to use [non-pharmacological strategies] during chemotherapy to deal with fatigue? Do you use any type of drug or treatment for fatigue that is not prescribed by your doctor? What kind of result have you achieved? From these questions, the researcher/interviewer and/or the participants, could diverge or formulate new questions necessary for detailing answers or for proceeding and deepening the reasoning. ${ }^{10}$

There were twenty interviews, six with Luiza and Lívia and four with Lis and Maya; they had a mean duration of 46 minutes and were transcribed by the principal investigator. The interval between the interviews went from 21 to 28 days, which corresponds to the interval between the chemotherapy cycles. 
In subsequent interviews, there was always a return with the participants about the topics covered in the previous interview, in order to resume points for clarification and/or deepening. This procedure allowed for the participants to clarify important aspects and validate the researchers' understanding, interpretations and pre-analysis. After reaching data saturation, but before leaving the field, participants were informed about and prepared for the closure of the meetings.

The method used to organize, analyze and describe the data was the thematic and inductive analysis. ${ }^{15}$ For the analysis, the interviews were transcribed and read repeatedly by the authors, in order to familiarize themselves with the content. Next, codifications and annotations of the initial ideas were made. Following these codes, based on the objective of the study, two major themes and seven sub-themes were outlined. This article is a master dissertation clipping, in which the analyzes of two subtopics are submitted.

\section{RESULTS}

The four women inhabited in the city where the oncologic clinic is found. Three are married and Luiza is a widow. All have adult children. Age range went from 43 to 65 years old. Schooling levels are diverse, as are occupations and religions. Table 1 shows their socio-demographic characteristics.

The four women received an anatomopathological diagnosis compatible with invasive ductal carcinoma and were submitted to the quadrantectomy type surgery and underwent chemotherapy with adjuvant intention. After ending chemotherapy, all women were referred to radiotherapy, and hormone therapy was recommended for three of them, except for Luiza. The other data diverged among them and are shown in Table 2.
In general, CSF has been described by women as feelings of discomfort, both physical and emotional. The reports focused on expressions such as fatigue and limitation when referring to physical fatigue; and mood changes, impatience, intolerance, headache and anguish, while sharing information on emotional fatigue.

Through the thematic analysis on the dataset about the women experiences with the management of CSF collected in the interviews and observations, the following sub-themes were identified: "Self-care in the management of physical fatigue" and "Self-care in the management of emotional fatigue".

\section{Self-care in managing physical fatigue}

The self-care strategies mentioned by the participants for the management of physical fatigue consisted of: rest, energy conservation and food care. The participants stated that rest, while providing momentary relief, is important to attenuate CSF. Among the three strategies, rest was the one that most stood out in the reports of the participants as an attempt to attenuate CSF:

Rest is a key factor. Every time I get tired I try to rest. [...] The result [is] good! Because I get up pretty well. [laughs]. (Luíza)

[...] the body itself asks you to lie down, quietly. (Lis)

Lis reports on the need to stay in a quiet environment with poor lighting and no noise. (Field Diary, June 27, 2015)

Every day, later in the afternoon, I want to lie down. I don't want to sleep, I want to lie down, just to rest. (Maya)

During an interview at her home, the participant Maya says that for relieving the fatigue, she lies down and elevates her lower limbs; she also reports that this practice makes her feel an improvement in the adverse reaction. (Field Diary, April 10, 2016)

Table 1. Socio-demographic characteristics regarding the study participants, oncology outpatient clinic of a public university hospital, MG, Brazil, 2017.

\begin{tabular}{|ccccc|}
\hline Pseudonym & Age & Schooling & Occupation & Religion \\
\hline Luíza & 65 & Incomplete Primary & Dressmaker (retired) & Jehovah's Witness \\
Lis & 47 & Higher education degree & Professor and coordinator of higher education & Catholic \\
Livia & 43 & Complete Secondary & Child Educator & Evangelical \\
Maya & 51 & Complete Secondary & Hammok Maker & Spiritist \\
\hline
\end{tabular}

Table 2. Clinical characteristics on the study participants, MG, Brazil, 2017.

\begin{tabular}{|cccccc|}
\hline Pseudonym & Period of Diagnosis & CS & Chemotherapy Protocol & Treatment Period & Interview Period \\
\hline Luíza & Aug. 2014 & I & AC-TH & $03 / 19$ to 09/23/2015 & $06 / 15$ to $10 / 25 / 2015$ \\
\hline Lis & Dec. 2014 & IIA & FAC & $14 / 04$ to 04/08/2015 & $06 / 23$ to $10 / 5 / 2015$ \\
\hline Livia & Nov. 2014 & IIA & AC-TH & $10 / 08 / 2015$ to 03/28/2016 & $01 / 16$ to 06/04/2016 \\
\hline Maya & Aug. 2015 & I & CMF & $01 / 19$ to 5/18/2016 & $04 / 10$ to 07/22/2016 \\
\hline
\end{tabular}

*Note: CS: clinical staging; AC-TH: antineoplastic doxorubicin and cyclophosphamide drugs, followed by paclitaxel or docetaxel, associated with the monoclonal antibody trastuzumab; FAC: antineoplastic fluorouracil, doxorubicin and cyclophosphamide; $\mathrm{CMF}$ antineoplastic cyclophosphamide, methotrexate and fluorouracil. 
This renews the state of mind. This moment I stop, rest, lie down a little [...] at least I was feeling calmer. It was not that I was not feeling [fatigue], it is that it became more tolerable, than if I went walking around, if I had been doing the normal activities. (Lívia)

Another described strategy was energy conservation, sometimes associated with rest. The informants performed their daily activities according to the body's tolerance and disposition, establishing its limits and its priorities:

[...] I lie down, rest and then I will do [...] some "little activity" at home, like this: catch, extend laundry, wash clothes and clean the kitchen. (Luíza)

[...] I'm doing what I can. Same as today, I 've already swept here, but then I felt myself a "little tired". (Lis)

Sometimes [fatigue] affects me, I remain so quiet, that the day that this happens, nor the food I make, I don't mess with anything. (Livia)

I laid a "little" here [on the coach], I watched the program [on TV], I said: "Oh, I'll see the program, then l'll finish [the household activities]". (Maya)

Food care represented by the consumption of certain food types, teas and juices, although not directly chosen for relieving CSF, was described by women as a way to prevent, attenuate or diminish undesirable effects and adverse reactions during the chemotherapy.

I feel myself fed, stronger, especially at the beginning [...] I took [green juices] all days, I made salads, I was feeling very well. In this last time, when I am not making use, especially of Ora-pro-nobis, it takes me longer to recover my energy; the issue of fatigue ... with chemotherapy effect going away. (Luíza)

The participant Luiza reports she makes Ora-pro-nobis juice, freezes it in small containers and prepares Ora-pro-nobis drink associated with banana, apple and papaya, becoming a vitamin or kale, lemon, apple and carrot, named by her as green juice. (Field Diary, 5/15/2015)

I use the green juice, yam, and spinach therapies in the sense of trying to boost my immune system because if it is low, consequently I will be tired and thus, this will not be good for my treatment. (Lis)

The green juice prepared by Lis is composed by mint, parsley and lemon, associated with ginger and yam. She also reported frequent use of mate tea to supplement oral hydration but, as a consequence, using the tea made herfeel very good and contributed to sleep. (Field Diary, 7/19/2015)

I was drinking passion fruit juice, honey, teas. Everything helped me stay [with the mind] calmer, [the body] more relaxed. (Lívia)
There are two days that I don't make it [ginger tea]. I think that's why my fatigue is more severe [...] [when I use the tea] I feel myself light, much less tired. The weight in the arms, in the legs diminishes enough, it is only that annoying "little pain". But, I get a lot better, my mood improves. (Maya)

\section{Self-care in managing emotional fatigue}

In addition to strategies to manage CSF in its physical dimension, the women mobilized non-pharmacological strategies to deal with the psychic dimension. Self-care practices for managing emotional fatigue were based on the participants' choices for walking, body movement, religious activities and gardening

The practice of religious activities was used by the participants as a resource to face the sickness and the reactions to breast cancer therapy, translated as a refuge for relieving CSF, especially in its emotional dimension. Religiousness was a strategy, in the midst of the limitations, to feel more calm and confident.

Limiting! [Fatigue] completely limits us, but it is a limit that we take to read the Bible, to read Torre de Vigia's publications. (Luíza)

It is so good [...] when I am reading [spirit books] I have nothing. I do not feel pain, I'm fine, I'm calm. I must have bought about six books since I started [the treatment], I read all of them thanks to God. (Maya)

When I was very fragile, people encouraged me; my brothers in the church prayed for me and visited me, seeking to remain together in the faith, giving a helping hand. It is in him [in God] that we acquire strength to overcome all the steps that we have to undergo in this treatment, which is not easy, but it is not impossible [laughs]. (Livia)

Before "chemotherapy" I lie down [on the bed], I put a song, a gospel, I will listen. I stay calm [...] it is a way for you to strengthen yourself, it has added in me the confidence in the treatment and the confidence to go through this process. (Lis)

Walking was practiced by Luiza and Maya. The first reported fatigue after the walk, while the second felt better. For both, walking was motivated by the quest for relief from emotional CSF and prevention of depression:

Saturday I already went to take a "walk" [...] / walk about two kilometers. [I feel] tired! Breathing short, very tired, I lie down there resting. I go out not because I'm okay! But it is in the attempt to move, not to be depressed! Because, it is to join cancer and to be quiet, depression comes for sure! (Luíza)

One of the things that is really relaxing me [emphatic in the speech] is walking, making me feel good [...] I am not tired, I am not anxious, I am not stressed, I feel good. I manage to develop the things [domestic activities], till [emphatic in the speech] a certain time also! (Maya) 
Moving the body was one of the resources that Lis and Maya used to deal with CSF in their quest to feel better, as explained in the following sections:

When I start going out [of the rest], I begin to get better. Even, sometimes, when my head is bad [headache], I lie in the net; sometimes, I go there, I water the plants a little... I think that this movement gives me some energy. (Lis)

[...] even though l'm doing something that will not solve anything, that will not lead to anything, I have to be on the move. Then I'll be fine. (Maya)

Gardening and contact with nature resulted in mental rest and in the opportunity to move to an environment outside the limits of their homes, where routines and daily living were held. These were strategies also practiced for managing emotional fatigue. According to the participants,

Green relaxes us. I come, look at a little plant, remove a dry leaf, and see if my orchids are flowering. This contact with green helps. For me, this area is a rest, because I go out, I almost don't stay indoors. (Lis)

[...] I will move a plant, I will change a pot plant [...] best thing is to mess with plants [...] it looks like l'm levitating! It's really great. (Maya)

\section{DISCUSSION}

The research's participants showheterogeneous socio-demographic characteristics. Age group, schooling, profession and religious orientations are distinct; such diversity permeates the population served in public healthcare institutions, in the different contexts where they live their experiences. This heterogeneity reflected in the singularities of discourses and in the ways where they have rescued from their culture the construction and utilization of strategies to face the biographical rupture caused by the disease and its treatment, which is understandable when we look at ourselves as ethnographers at the comprehensive presuppositions of the medical anthropology. ${ }^{16}$

It is through the ethnographic research that the different health behaviors and practices that permeate the therapeutic itinerary are apprehended. Observation leads the researcher to direct contact with what is lived by the participants in his study, in a privileged place - the context where they live - which allows to observe and follow the constant and continuous process of construction and reconstruction of meanings and actions, through the exchange of knowledge among individuals and groups. ${ }^{17}$

In chemotherapeutic treatment, adverse reactions and undesirable effects are perceived and felt quickly by the patients. The frequency of occurrences, whether due to the characteristics of the drug-related action, to the susceptibility of the organism or even to lack of knowledge about the forms for prevention and management, is high and considerable.
Patients and families mobilize significant strategies of their sociocultural context, and develop actions seeking to face and re-signify the new condition. Thus, explanatory models support this search for unconventional practices, be they complementary, integrative or even alternative, as a response to biographical rupture, imposed by the symptoms of adverse reactions. ${ }^{16,18}$

Fatigue, described by the participating women as an important and uncomfortable adverse reaction caused by chemotherapy, was highlighted as a cause for damage in different dimensions of life; in particular, for the physical and emotional dimensions. The subjective description displayed by the participants corroborates the definition of fatigue found in the literature, described by other cancer patients. ${ }^{3}$

When living the fatigue experience, the women established self-care strategies in order to relieve the symptoms of the reactions suffered as a result of the treatment, in order to resume the norma conditions essential to life, health and well-being, ${ }^{19}$ which can be understood with the comprehensive-interpretive approach of the health-disease-care process, based on the medical anthropology. ${ }^{20}$

The absence of a specific direction towards the proper fatigue management triggered in the participants a new awareness on the body itself, which became fragile in nature, requiring the mobilization of resources to face the new condition, which is in agreement with the implications of the rupture suffered at different levels. ${ }^{16}$ In this sense, the participants used three self-care strategies to deal with CSF in its physical dimension: rest, body energy conservation and food care. These strategies, identified in the cultural repertoire, were understood as possibilities for relief and for recovering normality. ${ }^{21-22}$

In the course of illness processes, normality and improvement in health conditions are usually associated with the possibility of carrying out activities of daily living, with a certain degree of autonomy and efficiency. ${ }^{21-22}$

In this perspective, we observed that women in this study performed extra-community activities, some with paid work, and others with voluntary religious activities, but always maintaining the roles of wives, mothers and household caretakers. It has been observed that these are still prominent as the main roles of women in the Western Culture, roles which remain strongly highlighted in the verbal reports. Not being able to exercise their roles, implied in physical and especially emotional and psychological harms. ${ }^{23}$

The desire for a return to normality, that is, to be able to carry out daily activities, was found in the reports when they referred to the fact that they felt they were limited for carrying them out. This social representation on the role of women found in the Brazilian society, as caretakers for their homes and relatives, may also influence the choices for non-pharmacological self-care practices, which are present in different sociocultural contexts. ${ }^{24}$

Among these strategies used, we observed rest as a referred key strategy and applied spontaneously by the participants in search for relief; even if momentary, given that CSF is not related to work and not being completely solved by the rest. ${ }^{1,3}$ They maintained it in a positive response to the experiences of CSF, ${ }^{25}$ because in some moments they felt better to perform the activities considered to be significant. 
This choice may have been a priority because of cultural knowledge, shared among the social groups, which involves rest as a possibility for relief of habitual fatigue. ${ }^{17}$ Another study, when evaluating the prevalence of fatigue in women with breast cancer submitted to chemotherapy, radiotherapy or post-treatment, identified rest and physical exercise as strategies that are more used to obtain relief, followed by distraction, rest, sleep, reading and food. ${ }^{2}$

Two other possibilities were described as important strategies to manage CSF in its physical dimension: body energy conservation and food care. Energy conservation consists of managing personal energy in order to prevent its loss. It is based on defining priority activities, performing them at the moment of more disposition and strength, interspersing with rest periods. One may choose to use equipment that is useful for carrying out activities, as well as delegating them to others. It is recommended to avoid long periods of daytime naps for not compromising the repairing night's sleep..$^{1,3}$

With regard to energy conservation, the participants indicated the suspension of domestic tasks, resting between activities and retirement at home, in order to avoid or aggravate the fatigue.

Health care through proper nutrition is a frequent and culturally valued practice; influenced by popular and familiar knowledge when the intention is to prevent or treat physical or mental disorders. Examples include teas, foods designated as "healthy", "whole" and "organic", ${ }^{8}$ applied as a resource to attenuate CSF, in addition to treating and/or preventing other adverse reactions resulting from chemotherapy.

The consumption of foods and herbs for therapeutic purposes influences the population's cultural behavior. ${ }^{26}$ In reporting food care as an important strategy to deal with adverse reactions to chemotherapy, women reinforce the influence of the popular knowledge and the family, which leads us to realize that eating involves the elaboration of new sensitivities, knowledge and experiences diffused in the context where people live, coexist, socialize and transit. ${ }^{27}$

Regarding self-care in managing CSF in the emotional dimension, the search for relief to the adverse reaction led to the use of three non-pharmacological strategies: practicing religious activities, walking/moving the body and taking care of plants.

The practice of religious activities was common to all women to deal with emotional CSF and feel confident about the therapy; which reinforces religiosity as a coping strategy throughout the oncological treatment. ${ }^{28-29} \mathrm{An}$ integrative review on the religious/ spiritual coping used by cancer patients on chemotherapy has shown improved well-being and contributed to the adherence to treatment and control of emotional changes. ${ }^{30}$

During the therapeutic trajectory, taking care of plants and practicing religious activities consisted in forms of distraction and relaxation that provided general relief for emotional CSF. This finding is corroborated by a pilot study with 22 patients with breast and lung cancer who underwent surgery, chemotherapy or radiotherapy one month after the end of treatment. The authors evaluated the use of the therapies related to contact with the nature, horticulture, meditation, yoga and support group therapy, for twelve weeks and highlighted improvement in quality of life and reduction in the fatigue. As a result, they considered such practices as useful for the emotional and spiritual well-being of the participants. ${ }^{31}$
In this study, two participants performed walks for fatigue relief. The practice of physical activity directed to improving emotional CSF also suited the need for socialization outside the home routine. The emotional benefits offered by walking and body movement to the women encouraged them to pursue these strategies in an attempt to attenuate the emotional CSF. A qualitative approach developed with women under chemotherapy observed that the reactions to the treatment, especially fatigue, were challenging for accomplishing physical activity, however, the participants found inner motivation to maintain the exercise due to the emotional and physical benefits. ${ }^{7}$

Recent meta-analysis reiterates these findings when confirming that physical exercise and psychological intervention are effective in reducing fatigue, and are significantly better than pharmacological options. Hence, they are indicated for managing cancer-related fatigue and its treatment. ${ }^{32} \mathrm{lt}$ is worth highlighting the cultural symbol for the performance of physical activity in a society where such practice is stimulated and is related to the sensation of well-being and/or to be healthy. ${ }^{8,25}$ In contrast, this strategy was not a priority in the options of our informants, which leads us to reflect on the need to have the professional skills and knowledge to guide patients about this practice in order to achieve better results.

Regarding the use of self-care strategies for fatigue management, it is worth mentioning a mixed study, which explored the use of non-pharmacological strategies by 362 patients with primary diagnosis of breast, colorectal, Hodgkin's and non-Hodgkin's lymphoma submitted to the chemotherapy. Upon analyzing the qualitative data, four categories emerged, which were based on self-care strategies: "Rest and relaxation", using rest, music and reading; "Remaining active" by practicing activities such as cycling, walking, swimming and golf, which have proved to be beneficial to physical disposition and emotional state; "Psychological wellbeing"; in this category, the participants sought to remain optimistic, used distractions and socialization, practiced yoga and meditation, maintained contact with nature and animals, and a healthy diet; and "support network" involving family, friends, professionals and religion to deal with the fatigue. These data reinforce that the discomforts generated by the fatigue negatively impact the physical and emotional dimensions of oncology patients, and lead to the search for unconventional self-care practices that alleviate CSF. ${ }^{33}$

Although the municipality, where the research herein described was developed, offers integrative and complementary practices (ICP) for free through the public health system, such as reiki, acupuncture, homeopathy, circular dance, reflexology and anthroposophy, ${ }^{34}$ we noted the absence of these practices among the participants in the research. This finding may be related to several factors, among which we cite: undervaluation of the ICP in the country, where pharmacotherapy prevails, and using biomedical technologies; scarcity of human resources, financial and institutional spaces for developing practices and, in particular, low disclosure for the population..$^{35}$ In addition to reiterating that, in the majority of cases, complementary practices and non-pharmacological strategies occur through stimulation and indication of the family, social or religious network, permeated and strengthened by the cultural influences. ${ }^{36}$ 
Given the biographical rupture caused by the cancer illness and the adverse reactions to chemotherapy, especially CSF, the women sought in their cultural repertoire non-pharmacological strategies for managing the fatigue. They discovered that their life experiences as women, mothers, and workers brought a knowledge that was still little explored by the health services, which gave them conditions to achieve relief, even if only momentary, reinforcing self-confidence through self-care, which made possible the continuity of the treatment to resume the normality in their life, this being the meaning that they attributed to their experiences.

\section{FINAL CONSIDERATIONS AND IMPLICATIONS FOR PRACTICE}

CSF is an uncomfortable, limiting and common adverse reaction in women with breast cancer. The demands generated by the treatment may cause physical, social and emotional losses that lead to the need for care and reorganization of the activities and routines of patients and close people that make up the social and family network.

The experiences of women with breast cancer undergoing intravenous chemotherapy in managing CSF, in their physical and emotional dimensions, were challenging and led to the search for non-pharmacological strategies that took advantage of the sociocultural and family repertoire, that is, of their beliefs, values, meanings, attitudes apprehended throughout their lives and in the conviviality with the people belonging to their environment. These strategies were expressed through selfcare, in an attempt to alleviate the discomforts generated and enabled the reduction of intensity and consequent attenuation of CSF, although momentary, reinforcing the importance of understanding the singularities of the context and the practices adopted to deal with this reaction adverse.

With regard to the contributions to the practice of individualcentered care, this study demonstrated the importance of valuing the discourses, knowledge, beliefs, values and practices that make sense for this population. The underreporting of CSF evidences the need to listen carefully to these women, with accurate and detailed records of the reports on the occurrence of CSF symptoms. In the practices of nursing care and of all professionals who assist these women, it is always appropriate to associate the understanding of knowledge and of the cultural practices with the scientific knowledge, so that the assistance with integral care may be developed and improved.

In this attempt, the qualitative methodology showed significant contributions, as it allowed to broaden the listening processes of the participants, to understand the meanings attributed to the experience and to their cultural care practices. Studies of this nature stimulate the reflection of professionals and researchers about the insertion of the patient in the caring process, encouraging and promoting actions to facilitate self-care, which compose the daily life of these women, being identified as a central strategy in managing CSF.
As a limitation of the study, it was not possible to address a greater diversity of integrative and complementary practices, although they are made available for free by the municipality. The participants' lack of knowledge about these services was noted. Thus, new studies with participants from different socio-cultural contexts are suggested, in order to increase the knowledge about using other types of non-pharmacological strategies in managing CSF.

\section{REFERENCES}

1. Bonassa EMA, Gato MIR. Terapêutica oncológica para enfermeiros e farmacêuticos. 4ª ed. São Paulo: Atheneu; 2012.

2. Panobianco MS, Magalhães PAP, Soares CR, Sampaio BAL, Almeida AM, Gozzo TO. Prevalence of depression and fatigue in a group of women with breast cancer. Rev Eletr Enferm [Internet]. 2012; [cited 2018 Jun 24]; 14(3):532-40. Available from: https://doi.org/10.5216/ree. v14i3.14409

3. National Comprehensive Cancer Network (NCCN). Cancer-Related Fatigue. NCCN Clinical Practice Guidelines in Oncology [Internet]. 2018 [cited 2018 Sep 30]. Available from: https://www.nccn.org/professionals/ physician_gls/f_guidelines.asp\#supportive

4. Radbruch L, Strasser F, Elsner F, Gonçalves JF, Loge J, Kaasa S, et al. Fatigue in palliative care patients - an EAPC approach. Palliat Med [Internet]. 2008 jan; [cited 2018 May 15]; 22(1):13-32. Available from: https://doi.org/10.1177/0269216307085183

5. Biswal BM, Sulaiman SA, Ismail HC, Zakaria H, Musa KI. Effect of Withania somnifera (Ashwagandha) on the development of chemotherapy-induced fatigue and quality of life in breast cancer patients. Integr Cancer Ther [Internet]. 2013 nov; [cited 2018 Jul 07]; 12(4):312-22. Available from: https://doi.org/10.1177/1534735412464551

6. Lyman $\mathrm{GH}$, Greenlee $\mathrm{H}$, Bohlke $\mathrm{K}$, et al. Integrative therapies during and after breast cancer treatment: ASCO Endorsement of the SIO Clinical Practice Guideline. J Clin Oncol [Internet]. 2018 sep; [cited 2018 May 27]; 36(25):2647-55. Available from: https://doi.org/10.1200/ JCO.2018.79.272

7. Ingram C, Wessel J, Courneya KS. Women's perceptions of home-based exercise performed during adjuvant chemotherapy for breast cancer. Eur J Oncol Nurs [Internet]. 2010 jul; [cited 2018 Jul 07]; 14(3):238-43. Available from: https://doi.org/10.1016/j.ejon.2010.01.027

8. Helman CG. Cultura, Saúde e Doença, notas de estudo de Medicina 5a ed. Porto Alegre: Artes Médicas; 2009

9. Good BJ, Fischer MMJ, Willen SS, Good MJDV. A reader in medica anthropology: theoretical trajectories, emergent realities. New Jersey: John Wiley \& Sons; 2010.

10. Pope $C$, Mays N. Pesquisa qualitativa na atenção à saúde. $3^{\underline{a}}$ ed. Porto Alegre: Artmed; 2009.

11. Geertz C. A interpretação das culturas. Rio de Janeiro: Guanabara Koogan; 1989

12. Associação Brasileira de Cuidados Paliativos. Consenso Brasileiro de Fadiga. Revista Brasileira de Cuidados Paliativos. 2010;3(2 Supp 1):S1-31

13. Mota DDCF, Pimenta CAM, Piper BF. Fatigue in Brazilian cancer patients, caregivers, and nursing students: a psychometric validation study of the Piper Fatigue Scale-Revised. Support Care Cancer [Internet] 2009 Jun; [cited 2018 May 25]; 17(6):645-52. Available from: https:// doi.org/10.1007/s00520-008-0518-X

14. Strauss A, Corbin J. Basics of Qualitative Research: Grounded Theory Procedures and Techniques. Newbury Park, CA: Sage Publications 1990.

15. Braun V, Clarke V. Using thematic analysis in psychology. Qual Res Psychol [Internet]. 2006; [cited 2018 Jun 06]; 3(2):77-101. Available from: http://dx.doi.org/10.1191/1478088706qp063oa 
16. López YAA, Trad LAB. "Before and after CML": illness experiences and dimensions of chronic myeloid leukemia as a biographical disruption. Cad Saúde Pública [Internet]. 2014 out; [cited 2019 May 20]; 30(10):21992208. Available from: $h$ ttp://dx.doi.org/10.1590/0102-311X00171613

17. Langdon EJ. The dialogues between anthropology and health: contributions to public policies. Ciênc Saúde Coletiva [Internet]. 2014 abr; [cited 2019 May 20]; 19(4):1019-29. Available from: https://doi. org/10.1590/1413-81232014194.22302013

18. Lima JF, Ceolin S, Pinto BK, Zilmmer JCV, Muniz RM, Schwartz E. Use of complementary and integrative therapies by oncology chemotherapy patients. Av Enferm [Internet]. 2015; [cited 2019 May 15]; 33(3):372-80. Available from: http://dx.doi.org/10.15446/av.enferm.v33n3.53363

19. George JB. Teorias de enfermagem: os fundamentos à prática profissional. $4^{\mathrm{a}}$ ed. Porto Alegre: Artmed; 2010.

20. Lira GV, Nations MK, Catrib AMF. Cronicidade e cuidados de saúde: o que a antropologia da saúde tem a nos ensinar?. Texto Contexto Enferm. 2004 jan/mar;13(1):147-55.

21. Lopes M, Nascimento LC, Zago MMF. Paradox of life among survivors of bladder cancer and treatments. Rev Esc Enferm USP [Internet]. 2016 apr; [cited 2018 May 25]; 50(2):222-9. Available from: http://dx.doi. org/10.1590/S0080-623420160000200007

22. Buetto LS, Zago MMF. Significados da qualidade de vida no contexto da quimioterapia pelo paciente com cáncer colorretal. Rev Latino-Am Nursing [Internet]. 2015 jun; [cited 2018 Jul 04];23(3):427-34. Available from: https://doi.org/10.1590/0104-1169.0455.2572

23. Anjos ACY, Zago MMF. The cancer chemotherapy experience in a patient's view. Rev Latino-Am Enfermagem [Internet]. 2006 fev; [cited 2018 May 25]; 14(1):33-40. Available from: http://dx.doi.org/10.1590/ S0104-11692006000100005

24. Silva GCC, Santos LM, Teixeira LA, Lustosa MA, Couto SCR, Vicente TA, et al. A mulher e sua posição na sociedade: da antiguidade aos dias atuais. Rev SBPH. 2005;8(2):65-76.

25. Langdon EJ, Wiik FB. Anthropology, health and illness: an introduction to the concept of culture applied to the health sciences. Rev Latino-Am Nursing [Internet]. 2010 jun; [cited 2018 May 08]; 18(3):459-66. Available from: https://doi.org/10.1590/S0104-11692010000300023

26. Antonio GD, Tesser CD, Moretti-Pires RO. Contributions of medicinal plants to care and health promotion in primary healthcare. Interface (Botucatu) [Internet]. 2013 set; [cited 2018 May 08]; 17(46):615-33. Available from: http://dx.doi.org/10.1590/S1414-32832013005000014

27. Carvalho MCVS, Luz MT, Prado SD. Eating, nourishment and nutrition: instrumental analytic categories in the scientific research field. Ciênc Saúde Coletiva [Internet]. 2011 jan; [cited 2018 May 08]; 16(1):155-63. Available from: http://dx.doi.org/10.1590/S1413-81232011000100019
28. Carvalho CC, Chaves ECL, lunes DH, Simão TP, Grasselli CSM, Braga CG. Effectiveness of prayer in reducing anxiety in cancer patients. Rev Esc Enfem USP [Internet]. 2014 aug; [cited 2018 Jun 06]; 48(4):683-90. Available from: http://dx.doi.org/10.1590/S0080623420140000400016

29. Almeida TG, Comasseto I, Alves KMC, Santos AAP, Silva JMO, Trezza MCSF. Experience of Young women with breast cancer and mastectomized. Esc Anna Nery [Internet]. 2015; [cited $2018 \mathrm{Jul} 07$ ]; 19(3):432-38. Available from: http://dx.doi.org/10.5935/14148145.20150057

30. Sousa FFPRD, Freitas SMFM, Farias AGS, Cunha MCSO, Araújo MFM, Veras VS. Religious/spiritual coping by people with cancer undergoing chemotherapy: integrative literature review. SMAD, Rev Eletrônica Saúde Mental Álcool Drog [Internet]. 2017 jan/mar; [cited 2018 Jun 26]; 13(1):45-51. Available from: https://doi.org/10.11606/ issn.1806-6976.v13i1p45-51

31. Magri MN, Imanishi J, Dagri JI, Watanabe S, Dagri Al, Baba T, et al. Spiritual care of cancer patients by integrated medicine in urban green space: a pilot study. Explore [Internet]. 2013 mar/apr; [cited 2018 Jul 20]; 9(2):87-90. Available from: https://doi.org/10.1016/j. explore.2012.12.002

32. Mustian KM, Alfano CM, Heckler C, Kleckner AS, Kleckner IR, Leach $\mathrm{CR}$, et al. Comparison of pharmaceutical, psychological, and exercise treatments for cancer-related fatigue: a meta-analysis. JAMA Oncol [Internet]. 2017 jul; [cited 2018 May 27]; 3(7):961-96. Available from: https://doi.org/10.1001/jamaoncol.2016.6914

33. O'Regan $P$, Hegarty J. The importance of self-care for fatigue amongst patients undergoing chemotherapy for primary cancer. Eur $\mathrm{J}$ Oncol Nurs [Internet]. 2017 jun; [cited 2019 May 15];28:47-55. Available from: http://dx.doi.org/10.1016/j.ejon.2017.02.005

34. Ministério da Saúde (BR). Portaria n. 849, de 27 de março de 2017. Inclui a arteterapia, ayurveda, biodança, dança circular, meditação, musicoterapia, naturopatia, osteopatia, quiropraxia, reflexoterapia, reiki, shantala, terapia comunitária integrativa e yoga à política nacional de práticas integrativas e complementares [Internet]. Diário Oficial da União, Brasília (DF). 27 mar 2017 [citado 20 mar 2018]. Disponível em: http://bvsms.saude.gov.br/bvs/saudelegis/gm/2017/ prt0849_28_03_2017.html

35. Lima CA, Santos AMVS, Messias RB, Costa FM, Barbosa DA, Silva CSO, et al. Integrative and complementary practices: use by community health agents in self-care. Rev Bras Enferm [Internet]. 2018 [cited 2019 May 14]; 71(Supl 6):2682-88. Available from: http://dx.doi. org/10.1590/0034-7167-2018-0078

36. Geertz C. O saber local: novos ensaios em antropologia interpretativa. Tradução de Vera Joscelyne. 14ª ed. Petrópolis: Vozes; 2014.

\footnotetext{
a Manuscript extracted from Master Dissertation: Experiências de mulheres com câncer de mama no manejo da fadiga secundária à quimioterapia. Defended by Nayara Ferreira Cunha, under the guidance of Anna Cláudia Yokoyama dos Anjos. 2017. Federal University of Uberlândia, School of Medicine, Post-graduation Program in Health Sciences.
} 